the building, which was completed in October $1895,1 \mathrm{~s}$ now being extended. The course of instruction covers four years : the first year is spent in the main building, in a general course of scientific study; the second is given up to physics, and the last two years are devoted to practical exercises in the electro-technic institute.

The chemical school is housed in another separate building, whichalso consists of two departments - the one for the study of pure chemistry, and the other for the study of chemical technology, electro-chemistry and pharmacy. The department for pure chemistry consists of three large laboratories for analysis and preparation work, and of a number of smaller laboratories for special researches. It has accommodation for sixty to seventy students. There are separate rooms for thermo-chemical, spectroscopic, photometric, and other physical experiments, as well as rooms for chemical investigations connected with secondary and other batteries.

The other side of the chemical school is mainly devoted to the study of electro-chemistry, and is equipped with the necessary apparatus and machinery, including continuous and alternating current dynamos, for experiments and researches in this special branch of applied chemistry.

The foregoing sketch gives only an outline of the facilities for the higher scientific education which are provided in the Darmstadt Institute, the most recently equipped of the many German technical high schools. The attendance of students during the recent summer semester is given as follows :-

\begin{tabular}{|c|c|c|c|}
\hline Departments. & $\begin{array}{l}\text { Regular } \\
\text { students. }\end{array}$ & $\begin{array}{l}\text { Occasional } \\
\text { students. }\end{array}$ & Total. \\
\hline $\begin{array}{lll}\text { Architecture } & \ldots & \ldots\end{array}$ & 74 & I 3 & 87 \\
\hline $\begin{array}{c}\text { Engineering and machine } \\
\text { construction }\end{array}$ & $35^{\mathrm{I}}$ & $3 i$ & 388 \\
\hline Electro-technology $\quad \ldots$ & 307 & 23 & 330 \\
\hline Chemistry ... $\quad \ldots$ & 89 & I3 & 102 \\
\hline General science & 29 & I8 & 47 \\
\hline & 850 & 104 & 954 \\
\hline
\end{tabular}

In the chemical department, 39 are returned as students in the electro-chemical section.

The teaching staff for these 954 students might seem to us excessive. It consists of 27 ordinary and of 6 extraordinary professors, of 22 demonstrators or instructors, and of 22 assistants, making a total of 77 . The students' fees vary from $£ 8$ to $£ \mathrm{I} 2$ a year, and the whole of the deficit on the cost of maintenance is defrayed by the State.

Philip Magnus.

\section{A VISIT TO AN ENGLISH WOAD MILL.}

$A$ REFERENCE to any old gazetteer under the name Wisbech will show that this town was once an important centre of the English woad industry. It is not generally known, however, that woad is still grown and worked up in a few localities, and it was with some surprise that we learnt that the processes connected with the manufacture might be seen in operation at Parson Drove, near Wisbech, at the present time. There are said to be three other places where the plant is cultivated and worked up for use by dyers-one near Boston and two near Holbeach, in Lincolnshire; but at these centres the introduction of steam power has destroyed the primitive character of the manufacture. As an interesting survival of the past, the mill at Parson Drove is well worthy of a visit.

$$
\text { NO. I } 4 \text { I I, VOL. 55] }
$$

It is hardly to be expected that a feeble tinctorial substance, such as woad, can retain a permanent footing as an English product in view of the circumstance that it has to compete with indigo, as well as with its modern coal-tar substitutes. The thought that this old-time industry, like the potash-making in Essex, ${ }^{1}$ is sooner or later destined to become extinct, has led us to place upon record the information which we gathered during a visit to the Parson Drove mill in July of this year. We may add that descriptions of this mill were given in the Gardeners' Chronicle in $188 \mathrm{I}^{2}$ and $\mathrm{I} 882$; but, as we obtained later and more detailed statements on the spot, concerning the actual operations as now conducted, it may be of interest to chronicle the facts once again while it is still possible to get particulars from the woadmen at first hand.

The leaves of the plant (Isatis tinctoria) are wrenched off at the base by the pickers, the root being left undisturbed, so as to permit the growth of a second crop. The first process consists in crushing the leaves to a pulp under rollers. The latter, of which there are three at the Parson Drove mill, are hollow, slightly conical, wooden drums, with about two dozen iron cross-bars arranged round the circumference, these iron bars furnishing the effective crushing edges. The three rollers are geared to a long projecting horizontal pole, which is made to move round by means of a horse. The pulpy mass resulting from the crushing operation is then kneaded by hand into balls, about the size of cricketballs, on a wooden stage, the balls, when made, being placed in three rows on wooden trays, which, as they are packed, are pushed up a sloping plank till high enough to go on to the head of a man who stands at the end to receive them. Each tray, as it is delivered, is carried to the drying sheds. The balls are allowed to dry in the air for about four weeks, and are for this purpose transferred from the trays to wooden gratings arranged in tiers in the roofed, open framework sheds, known locally as "ranges" (shown in the illustration). When dry, the balls are again ground up under the rollers, and the material then conveyed to the floor of another roofed shed, where it is sprinkled with water, and allowed to ferment for a period of nine weeks. The shed in which this process goes on is known as the "couching-house." The fermenting mass is constantly turned over by the workmen, and water added from time to time. We were told that the fermentation is at first very vigorous, the mass getting quite hot and steaming. At the end of the process in the couching-house the woad is ready for the market, and is simply packed tightly into wooden casks for sending away.

The primitive character of the manufacture makes it not only of interest as a lingering survival of an ancient rural industry; but the antiquarian and lover of folk-lore may derive instruction from the mode of construction of the rough sheds, and from the technicalities used by the workmen. Thus the term "couching" is used in a similar sense by maltsters, and is no doubt a Norman survival (Fr. Coucher); the sloping plank is called the "firm" (? form), and the tray on which the pulp is kneaded is known as the "balling-horse." The balls were formerly dried on wattles, known as "fleaks," a term apparently identical with the word still used for hurdles in Scotland; but these are no longer used at Parson Drove. The central circular shed containing the rollers is built of wooden planks and posts, and thatched with a conical roof; the lateral couching-house is constructed of thick turf walls, with the slabs arranged in a peculiar herring-bone form, and also roofed with thatch.

1 See a paper by Henry Laver in the Essex Naturalist, vol. 1x. p. Irg. 2 The writer of this article acknowledges, as the source of his information, a recent paper in the Friends' Quarterly Examine\%. An interesting popular account of the mill appeared in Aunt Judy's Anmual volume in $188_{3}$. 
The whole construction was evidently framed with a view to cheapness and simplicity, so as to be easily removable. In the palmy days of the industry the sheds were not permanent erections, but were moved about from one place to another, so as to be near the crops.

We content ourselves with recording the bare facts without comment or criticism. Any science that lurks behind this ancient manufacture has been found out empirically, and handed down by tradition from a remote past. The imaginative person may indulge his fancy by carrying back the woad industry to that period when the early inhabitants of this country furnished that solitary scrap of personal information which is still the historical stock-in-trade of the average schoolboy. It may be well, however, to point out in this connection that Isatis tinctoria appears not to be a native of Britain. ${ }^{1}$ We were told that in former times the woad-men a zymolytic decomposition of glucosides. The use of woad as a source of indigo is now very limited, being confined to some of the old-fashioned Yorkshire dyehouses, where it is used in conjunction with indigo in the so-called "woad vat," a description of which will be found in any work on dyeing.

FRANCIS DARWIN. R. MELDOLA.

\section{NOTES}

THE Royal Society's medals have this year been adjudicated by the President and Council as follows:--The Copley medal to Prof. Carl Gegenbaur, For.Mem.R.S., for his researches in comparative anatomy, and especially in the history of the vertebrate skeleton; the Rumford medal to Prof. Philipp Lenard,

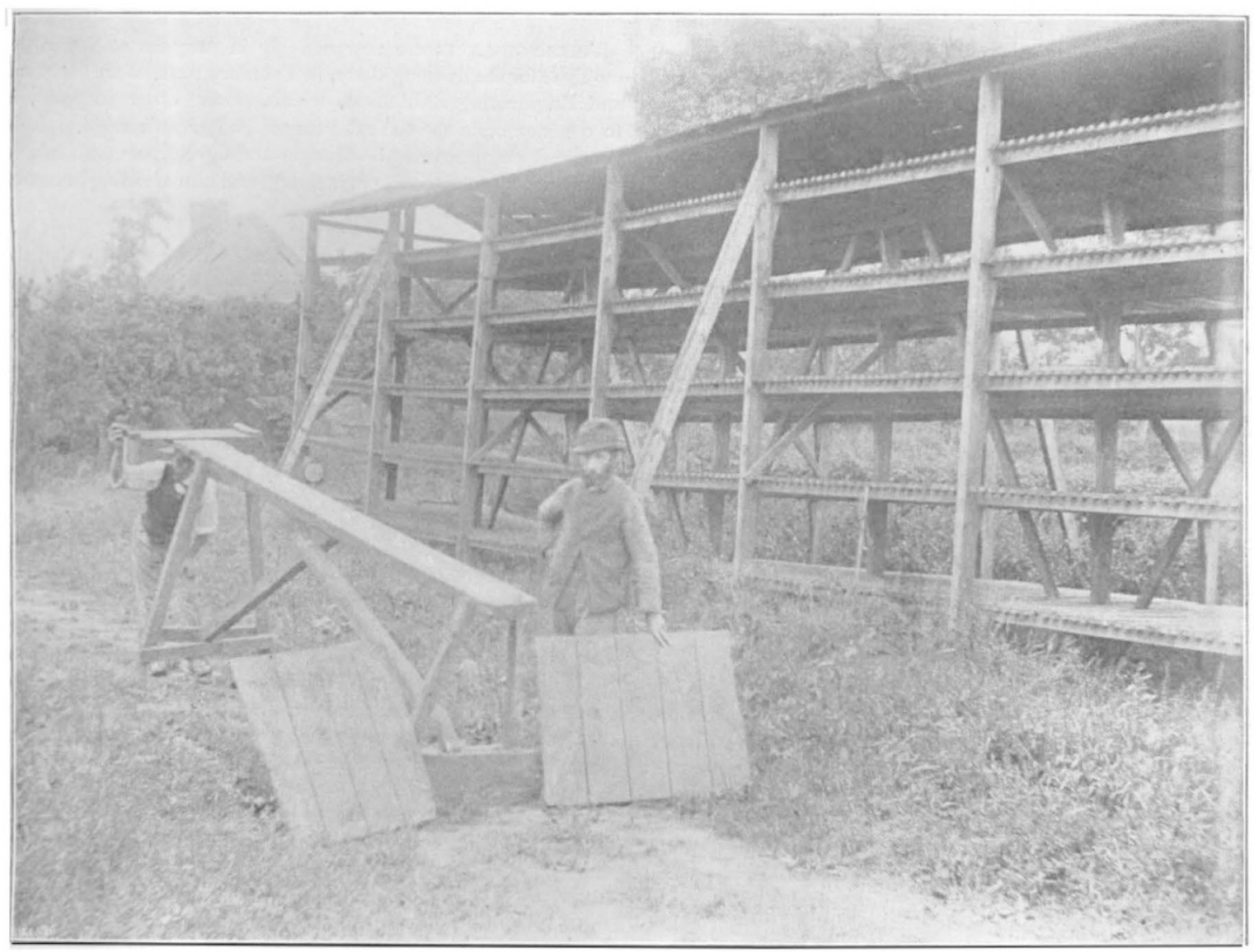

Woad Mill at Parson Drove. Two "balling-horses" are shown in front; between them is the "firm," from the further end of which a man is lifting one of the trays on which the balls are carried to the "ranges" ; the latter are shown on the right

were limited to certain families, and that they had traditional chants of their own; but these are passing into oblivion, and we were unable to ascertain the words. The object of drying the pulp first, and then wetting it again before allowing it to ferment, is not at first sight obvious, nor could we learn why this practice has been found advantageous. The fermentation itself is no doubt

1 In the "Flora of the British Islands" (ed. 1870), Hooker says: "The ancient Britons stained themselves with this plant; later the Saxons imported it." Can it be that even at that remote period the British colour industry could not hold out against continental competition?

2 A verse is recorded by Miss Peckover in the article in Aunt Judy's Anntal volume for $188_{3}$, p. 549 . and also to Prof. Wilhelm Conrad Röntgen, for their investigation of the phenomena produced outside a highly exhausted vacuum tube through which electrical discharge is taking place; a Royal medal to Sir Archibald Geikie, F.R.S., on account of the great value and importance of his many original contributions to geology; a Royal medal to Prof. Charles Vernon Boys, F.R.S., for his invention of quartz fibres and investigation of their properties, his improvement of the radiomicrometer and investigations with it, for developments in the art of instantaneous photography, and for his determination of the value of the constant of attraction; the Davy medal to

NO. I4I I, VOL. 55] 